\title{
Patient Knowledge and Understanding of Home Health Services Criteria
}

Philip B. Collins, DO'; Stuti Jha, PhD²; Alison Mancuso, DO, FACOFP'; John F. Bertagnolli, Jr., DO'; Sondra M. De Antonio, MD'; John Galezniak, DO; Kathryn M. Montgomery, OMS II'; Lt. Rohith R. Kothakapu, OMS II

\author{
'Rowan University School of Osteopathic Medicine, Stratford, NJ \\ ${ }^{2}$ Rowan University, Glassboro, NJ \\ ${ }^{3}$ Lourdes Medical Associates, Camden, NJ
}

\section{KEYWORDS:}

Home Health

House Call

Homebound Criteria
ABSTRACT: Context: This study was conducted to gain a better understanding of patients' understanding of homebound criteria and house call eligibility.

OBJECTIVE: To date, little empirical data exists assessing patient knowledge of home health care services. This study is designed to examine patients' understanding of home health care services, eligibility criteria, costs, and interest in house calls.

METHODS: This study used an anonymous survey developed by the researchers and provided to patients in four separate office locations at a large academic Family Medicine practice. Questions about homebound criteria, eligibility, out of pocket cost, and patient interest were asked.

RESULTS: In total 393 surveys were collected. Approximately 47 percent of all respondents in the survey showed interest in having a home care visit by a healthcare professional, while only 59.6 percent were able to accurately identify the definition of homebound status. Approximately 60 percent of all respondents believe that they will have to pay more out of pocket for home visits, and the subgroup of respondents who have an interest in home visits showed that 63.4 percent of that group think that they will have to pay more out of pocket for such visits.

CONCLUSION: These data have the potential to inform medical providers of a lack of understanding among patients regarding homebound criteria and home health care in general. While further studies could examine more specific details of this potential knowledge gap, the information provided by this study could prompt providers to begin educating patients on the possibility of home care.

\section{INTRODUCTION}

The population of Americans age 65 and older is approximately 49 million and rising. ${ }^{1}$ It is estimated that among those living in the community in this age range, $19.6 \%$ are homebound. ${ }^{2}$ Compared to their non-homebound peers, homebound seniors have been

\section{CORRESPONDENCE:}

Philip B. Collins, DO | collinsp@rowan.edu shown to have significantly higher health care expenditures and number of hospitalizations. Homebound status can also predict future depressed affect in addition to difficulties with activities of daily living (ADL) and instrumental activities of daily living (IADL). ${ }^{3}$ Despite evidence indicating homebound individuals are more likely to have been hospitalized in the last year and have more chronic conditions, such as heart failure, emphysema, stroke, dementia, and depression, estimates suggest that only $11.9 \%$ of homebound patients receive home care..$^{4,5}$ In addition to the increased likelihood of the aforementioned chronic conditions, 
homebound patients over the age of 65 have a mortality rate of $40.3 \%$ compared to $5.8 \%$ seniors not homebound, independent of comorbidities. ${ }^{6}$

Homebound status can carry varying definitions. The Centers for Medicare and Medicaid Services (CMS) criteria that patients must meet in order to be considered homebound are defined as follows:

\section{Each of the following criteria must be met:}

- There must exist a normal inability to leave home

- Leaving home must require a considerable and taxing effort

Additionally, one of the following criteria must be met:

- Because of illness or injury, need the aid of supportive devices such as crutches, canes, wheelchairs, and walkers

- The use of special transportation or the assistance of another person to leave their place of residence

- Have a condition such that leaving his or her home is medically contraindicated.

In addition to these criteria the patient may be considered homebound if absences from the home are: infrequent, for periods of relatively short duration, for the need to receive health care treatment, for religious services, to attend adult day care programs, or for other unique or infrequent events (i.e. funeral, graduation, trip to the barber). ${ }^{7}$

Identifying these patients requires a medical professional to determine that the above criteria are met. Promoting the possibility of physician house calls to patients could prove to be helpful, though there is currently little known about the extent of patients' knowledge of home care and homebound criteria. In many cases there are options available to homebound patients to receive quality, cost-effective healthcare at home including skilled nursing services, physical and occupational therapy, and visits from physicians. ${ }^{7}$ Introducing these at-home services early in disease progression can be beneficial as it has been shown that house call intervention at a younger age can lead to better outcomes. ${ }^{8}$

In addition to the health outcome benefits, house calls have been shown to reduce overall health care spending among homebound patients.9,10,11 A 2014 systematic review of home-based primary care programs for older homebound adults enrolled in services showed several positive benefits to home health care including reduction in emergency room visits, hospitalizations, and long term care admissions compared to those non-enrolled. Furthermore, it showed a cost savings of $24 \%(\$ 29,000$ to $\$ 38,000)$ over a year. ${ }^{12}$

To our knowledge, there have been no studies evaluating patients' familiarity with home health in the US; however, one study based in Turkey found that only $54.9 \%$ of patients 65 or older are familiar with the concept of home health care. ${ }^{13}$ Additionally, the Centers for Disease Control and Prevention (CDC) estimates that home health care is only utilized by 75 in 1000 patients over the age of 65 in the United States. ${ }^{14}$ This low number could be due to a variety of factors. In this study we set out to explore the reasons for this low utilization rate and, among other things, we also examine the role of information and perception of house calls and home health care. We aimed to assess patients' knowledge of homebound criteria, potential perceived barriers such as out of pocket costs, and whether there are any knowledge disparities related to age or race.

\section{METHODS}

The researchers developed an anonymous 13-item multiplechoice survey and provided it to adult patients age 18 and older at four office locations within a large academic Family Medicine practice located in the mid-Atlantic region of the country. Demographic information including age, race, and gender were collected. In order to more effectively observe whether or not patients seek out information about physician house calls as they grow older, all age groups of patients were included. Questions included items that judged subjects' knowledge of qualifying and disqualifying criteria for homebound medical status eligibility. The survey also contained questions about participants' interest in home health care, the definition of homebound, which services are provided by home health care, the out of pocket cost of home care, and participants' perception of the level of care provided at home. To avoid confusing and lengthy questions, the definition of homebound on the survey was described as "it takes considerable effort to leave home." While this definition does not fully meet criteria set out by CMS, it does roughly approximate the criteria.

The logistics regression model and marginal effects were used to examine patient knowledge of home health care. For simplicity, only the respondents who showed interest in home visits were utilized for this analysis.

\section{Regression equation:}

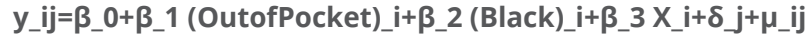

Where $y$ is the binary variable, which takes the value 1 if the respondent $\mathrm{i}$ chose the correct answer, and 0 if the respondent chose a wrong answer. "Out of pocket", our main variable of interest, is a binary variable, which takes the value 1 if the respondent believes that a home health visit will include out of pocket expenses, and 0 otherwise. Black is a binary variable for race. $X$ is the vector of demographic characteristics like age and gender. We control the regression for location fixed effects, which is represented by $\delta_{-} \mathrm{j}$. Since this is a logistic regression, we are interested in the marginal effects of the variables instead of the coefficients.

\section{RESULTS}

In total, 393 surveys were collected. The survey questioned the respondents on their interest in and their knowledge of the eligibility criteria for a home visit by a healthcare professional. Table 1 gives the summary statistics of some of the main variables of interest. The variables are binary with value 0 or 1. A variable takes the value 1 if the respondent chooses "Yes" as the answer to a question, and it takes the value 0 if the respondent chooses "No" as the answer to a question. For the race/demographic variables, 


\section{TABLE 1:}

Summary statistics

\begin{tabular}{|c|c|}
\hline Variables & $\begin{array}{l}\text { Percentage Selecting } \\
\text { Answer Choice }\end{array}$ \\
\hline $\begin{array}{l}\text { Respondents who are interested } \\
\text { in home visits }\end{array}$ & $46.6 \%$ \\
\hline $\begin{array}{l}\text { Respondents who are not interested } \\
\text { in home visits }\end{array}$ & $53.4 \%$ \\
\hline \multicolumn{2}{|l|}{ Eligibility related questions } \\
\hline Definition never able to leave my house & $37.6 \%$ \\
\hline Definition have less than 6 months to live & $1.5 \%$ \\
\hline $\begin{array}{l}\text { Definition leaving my home requires } \\
\text { considerable effort }\end{array}$ & $59.6 \%$ \\
\hline \multicolumn{2}{|l|}{ Information } \\
\hline Out of Pocket Expense is more than office & $60.2 \%$ \\
\hline $\begin{array}{l}\text { Out of Pocket Expense is more than office for } \\
\text { group interested in home visit }\end{array}$ & $63.4 \%$ \\
\hline \multicolumn{2}{|l|}{ Demographic Characteristics } \\
\hline White & $72 \%$ \\
\hline Black & $14.2 \%$ \\
\hline Hispanic & $7.3 \%$ \\
\hline Asian & $1.2 \%$ \\
\hline Male & $35.6 \%$ \\
\hline Female & $64.4 \%$ \\
\hline
\end{tabular}

it takes value 1 if the respondent belongs to that particular race/ demographic category, it takes the value 0 otherwise.

Approximately 47 percent of all respondents in the survey showed interest in having a home care visit by a healthcare professional. The next question on the survey, related to the definition of homebound status, gave respondents three different options concerning the definition of homebound status for which they were asked to check the correct answer. Most respondents (59.6 percent) chose the most accurate answer, "leaving my home requires considerable effort" while 37.6 percent chose "never able to leave my house" and 1.5 percent chose "less than six months to live."

Another variable of interest is what patients consider to be the cost of home visits. Approximately 60 percent of all respondents believe that they will have to pay more out of pocket for home visits. The subgroup of respondents who had interest in home visits, showed that 63.4 percent of that group think that they will have to pay more out of pocket for such visits. In reality, however, home care visits are covered by many insurers, including Medicare, with similar cost as office visits. ${ }^{15}$

The last few variables examined are demographic characteristics of the respondents. 72 percent of all respondents identified as White, 14.2 percent identified as Black, and approximately 7 percent identified as Latino. Though there is a slight over sampling of participants identifying as female with only 36 percent of all respondents identifying as male, that should not affect the results because there is not an identifiable gender difference in the responses.

Table 2 provides demographic characteristics of patients in various age groups. There are seven different age cohorts ranging from 18 years to 75 years and above. Racial distribution of the respondents was similar across groups, except the 35 to 44 year age group, which had a higher proportion of Hispanic patients. Another age cohort, 65 to 74 years old, had no Hispanic respondents. There were fewer males in every age cohort. A possible explanation is that fewer males agreed to fill out the survey.

We included all age groups in the analysis to observe if there is a learning curve among the population, postulating that as people get older they gather more information about home visits because they usually need assistance around that time. The results for all the age groups look similar. The number of respondents picking the correct answer choice or showing interest in house calls does not change significantly with age.

Respondents who indicated that they were interested in house calls were more likely to accurately identify the correct homebound definition, Table 3.

The likelihood of someone showing interest in home visits was then evaluated based on demographic information. Participants identifying as White represented the largest subgroup in the category of race, hence it was used as the control group and then compared to other racial subgroups. Participants identifying as Black were more likely to be interested in home visits, Table 4.

Table 5 shows the results from the logistic regression along with its marginal effects where the dependent variable is the correct choice for eligibility question on the survey and the independent variable refers to the question about people's knowledge about cost of home visits. The regressions only include respondents who showed interest in a home health visit. The second column above includes the marginal effects of the logistics regression.

\section{DISCUSSION}

A recent study found that only $54.9 \%$ of patients aged 65 or older are aware of the concept of home health care, indicating an overall lack of knowledge. The findings reported in the current study support these prior results by identifying about $40 \%$ of participants were not aware of the homebound definition. ${ }^{13}$ It should be noted the former study was based out of Turkey, where the health care system may vary from that of the US, but 


\section{TABLE 2 :}

Summary statistics by age

\begin{tabular}{|c|c|c|c|c|c|c|c|}
\hline Variables & $18-24$ years & $25-34$ years & $35-44$ years & $45-54$ years & $55-64$ years & $65-74$ years & $65-74$ years \\
\hline Number of Responses & 20 & 45 & 57 & 90 & 85 & 59 & 59 \\
\hline $\begin{array}{l}\text { Respondents who show } \\
\text { interest in home visit. }\end{array}$ & 0.4 & 0.42 & 0.493 & 0.44 & 0.51 & 0.44 & 0.44 \\
\hline \multicolumn{8}{|l|}{ Eligibility related questions } \\
\hline $\begin{array}{l}\text { Definition leaving my home } \\
\text { requires considerable effort } \\
\text { (correct answer) }\end{array}$ & 0.45 & 0.62 & 0.42 & 0.633 & 0.61 & 0.49 & 0.49 \\
\hline \multicolumn{8}{|l|}{ Information } \\
\hline $\begin{array}{l}\text { Patient believes out of pocket } \\
\text { cost is higher }\end{array}$ & 1 & 0.53 & 0.63 & 0.606 & 0.55 & 0.52 & 0.52 \\
\hline $\begin{array}{l}\text { Patient believes the quality of } \\
\text { care received during house calls } \\
\text { is better than doctor's office }\end{array}$ & 0.88 & 0.52 & 0.66 & 0.789 & 0.695 & 0.64 & 0.64 \\
\hline \multicolumn{8}{|l|}{ Demographic Characteristics } \\
\hline White & 0.80 & 0.62 & 0.72 & 0.72 & 0.715 & 0.88 & 0.88 \\
\hline Black & 0.15 & 0.117 & 0.088 & 0.176 & 0.141 & 0.101 & 0.101 \\
\hline Hispanic & 0.05 & 0.155 & 0.14 & 0.077 & 0.058 & 0 & 0 \\
\hline Asian & 0 & 0.022 & 0.017 & 0 & 0.011 & 0.016 & 0.016 \\
\hline Male & 0.55 & 0.244 & 0.403 & 0.344 & 0.388 & 0.378 & 0.378 \\
\hline
\end{tabular}

\section{TABLE 3 :}

Regression results - interest in home visits

\begin{tabular}{|l|l|l|l|l|}
\hline Variables & Correlation & Logit Regression Coefficient & P-Value & Statistical Significance \\
\hline Definition never able to leave my house & -0.057 & -0.290 & 0.170 & No \\
\hline Definition have less than 6 months to live & 0.052 & 0.841 & 0.335 & No \\
\hline $\begin{array}{l}\text { Definition leaving my home requires } \\
\text { considerable effort }\end{array}$ & 0.109 & 0.413 & 0.046 & Yes (at 5\%) \\
\hline
\end{tabular}

Notes: The table shows the correlation between the variable "interest in home visit" and the three answer choices for the definition of homebound. The regressions were run without any controls. All the variables are binary variables. 


\section{TABLE 4 :}

Interest in Home Visits by Race

\begin{tabular}{|l|l|l|l|}
\hline Variable Name & Coefficient & P-Value & Statistical Significance \\
\hline Black & 0.632 & 0.032 & Yes \\
\hline Hispanic & 0.415 & 0.295 & No \\
\hline Asian & 1.37 & 0.238 & No \\
\hline
\end{tabular}

Notes: All the variables indicating various races have a positive correlation, however, the coefficient on the variable "Black" is significant. This indicates that Black respondents are more likely to show interest in these services.

\section{TABLE 5 :}

Logistic Regression Results - Homebound Criteria Correctly Identified

\begin{tabular}{|c|c|c|}
\hline & Logistical Regression & Marginal Effects \\
\hline Variables & \multicolumn{2}{|c|}{ Choice: Leaving Home takes Considerable Effort } \\
\hline Out of pocket & -0.574 & $-0.139 *$ \\
\hline S.E. & $(0.375)$ & $(0.0871)$ \\
\hline Black & $-0.789 *$ & $-0.2007^{*}$ \\
\hline S.E. & $(0.445)$ & $(0.103)$ \\
\hline Hispanic & -0.706 & -0.166 \\
\hline S.E. & $(0.584)$ & $(0.143)$ \\
\hline Male & 0.0356 & 0.016 \\
\hline S.E. & $(0.372)$ & $(0.083)$ \\
\hline Age -18 to 24 years & 1.002 & 0.213 \\
\hline S.E. & $(0.873)$ & $(0.134)$ \\
\hline Age -25 to 34 years & 0.187 & 0.062 \\
\hline S.E. & (0.551) & (0.121) \\
\hline Age -35 to 44 years & -0.157 & 0.031 \\
\hline S.E. & $(0.517)$ & $(0.121)$ \\
\hline Age -55 to 64 years & $0.775^{*}$ & $0.174^{*}$ \\
\hline S.E. & (0.461) & $(0.091)$ \\
\hline Age -65 to 74 years & -0.271 & -0.0657 \\
\hline S.E. & $(0.514)$ & (0.121) \\
\hline Constant & $-0.680^{* *}$ & \\
\hline S.E. & $(0.309)$ & \\
\hline Observations & 173 & 173 \\
\hline
\end{tabular}

${ }^{*}=$ significance at $10 \% ;{ }^{* *}=$ significance at $5 \% ;{ }^{* * *}=$ significance at $1 \%$ Notes: The dependent variable is a binary variable that represents correct choice for the eligibility criteria for house calls. We find the marginal effects (change in probabilities) of our main variable of interest, that is, patients who think house calls will cost them more out of pocket than an office visit.

Age group 75 years and above is the control group. Age group 45 to 54 years was dropped in the model (by STATA). This could be because of multicollinearity. interestingly a large number of participants were not familiar with home care services in either study. Additionally, our findings show that this knowledge gap is not limited to people age 65 and older but is present among adults of all ages. This result is worth noting given that many caregivers of elderly patients are under the age of 65 .

A majority of participants (60.2\%) in this study, and $63.4 \%$ of respondents who are interested in house calls, believe it costs more out of pocket. While the actual out of pocket costs may vary based on insurance carrier/plan, typically there are no additional costs to the patient. ${ }^{15}$ The misconception of increased costs could certainly deter patients from seeking house calls, even if interested. Educating patients could clear up this fallacy.

In this study, most people who indicated interest in home health care chose the correct answer when identifying its definition and, as evident in Table 1, the coefficient is statistically significant. This finding is not surprising and may be explained by the possibility that patients are interested because they are more knowledgeable of the criteria and what house calls entail. Interestingly, there still remains a disparity of knowledge even among those who are interested in house calls and accurately identifying homebound status. Our results indicate that this group of participants is still less likely to identify out of pocket costs as being similar to office visits. The logistics regression and the marginal effects show how the probability of one of these events changes for the respondents who choose the correct answer. The marginal effect on the variable "out of pocket" is -0.139 , meaning that if someone shows interest in home health visits and that respondent chooses the correct eligibility criteria, then their probability of claiming additional out of pocket expenditure for such visits decreases by almost $14 \%$, Table 5. However, while interesting, this number is still quite low from an economic significance. It is possible that a large portion of the eligible population doesn't look for home visit information, as they mistakenly think that it will cost them more out of pocket. It should also be noted that interest in house calls does not change with age. This is an interesting observation, and it underscores the importance of raising awareness among the elderly patients about home visit options available to them.

Another important take away from Table 5 is the result for the Black respondents in the sample. From Table 4, we note that Black respondents were more likely to show interest in home health visits. However, we see a lack of information among the same group on the eligibility criteria for such visits. They were 20 percent less likely to select the correct choice for the eligibility criteria, as shown in Table 5. While there are several potential reasons for this, one would need to consider if there is a lack of information among the community.

It should be noted that this study was done in an academic practice that actually has a house call department, which potentially led to an increase in overall knowledge among participants. The patients surveyed were not housecall patients, as this is a separate department, but it would be interesting to see a future similar study performed at a practice without a house call department. Other limitations of this study include a lack of equal racial distribution across age groups and the fact that the majority of respondents identified as white. 
Future research should focus on the race-related knowledge disparities seen in this study. Additionally, research aimed at finding the best way to educate patients on homebound criteria and other related details such as cost and services may prove to be a helpful way to increase home care utilization.

\section{CONCLUSIONS}

To our knowledge, this is the first study that looks at the effect of misinformation on the usage of home health care services by patients. There is clearly a gap in the literature and this study contributes towards reducing this gap. These data have the potential to help inform providers that there may be a lack of understanding and awareness among patients in regard to home health care eligibility. This study found that there might exist a knowledge gap in regards to homebound status definition and the cost of house calls. While there may be specific details with each patient that may or may not qualify someone for home care, many of the participants in this study were not aware of at least some of the criteria or details of home health care indicating a possible knowledge gap. Educating patients about eligibility and details could potentially lead to more patients seeking home health care and understanding the reasons for such low rate of usage among the population is important to take steps to increase awareness and access.

\section{AUTHOR DISCLOSURES:}

No relevant financial affiliations or conflicts of interest.

\section{REFERENCES:}

1. Roberts AW, Ogunwole SU, Blakeslee L, Rabe MA. The Population 65 Years and Older in the United States: 2016. American Community Survey Reports. https://www.census.gov/content/dam/Census/library/ publications/2018/acs/ACS-38.pdf. Published October 2018. Accessed November 23, 2018.

2. Musich S, Wang SS, Hawkins K, Yeh CS. Homebound older adults: Prevalence, characteristics, health care utilization and quality of care. Geriatric Nursing. 2015;36(6):445-450. doi:10.1016/j. gerinurse.2015.06.013.

3. Cohen-Mansfield J, Shmotkin D, Hazan H. The Effect of Homebound Status on Older Persons. Journal of the American Geriatrics Society. 2010;58(12):2358-2362. doi:10.1111/j.1532-5415.2010.03172.x.

4. Ornstein KA, Leff B, Covinsky KE, et al. Epidemiology of the Homebound Population in the United States. JAMA Internal Medicine. 2015;175(7):1180-1186. doi:10.1001/jamainternmed.2015.1849.

5. Qiu WQ, Dean M, Liu T, et al. Physical and Mental Health of Homebound Older Adults: An Overlooked Population. Journal of the American Geriatrics Society. 2010;58(12):2423-2428. doi:10.1111/j.15325415.2010.03161.x.

6. Soones T, Federman A, Leff B, Siu AL, Ornstein K. Two-Year Mortality in Homebound Older Adults: An Analysis of the National Health and Aging Trends Study. Journal of the American Geriatrics Society. 2017;65(1):123129. doi:10.1111/jgs.14467.

7. Certifying Patients for the Medicare Home Health Benefit. Certifying Patients for the Medicare Home Health Benefit. https://www.cms.gov/
Outreach-and-Education/Outreach/NPC/Downloads/2014-12-16HHBenefit-HL.pdf. Accessed November 23, 2018.

8. Stuck AE, Egger M, Hammer A, Minder CE, Beck JC. Home Visits to Prevent Nursing Home Admission and Functional Decline in Elderly People. Jama. 2002;287(8):1022-1028. doi:10.1001/jama.287.8.1022.

9. Melnick GA, Green L, Rich J. House Calls: California Program For Homebound Patients Reduces Monthly Spending, Delivers Meaningful Care. Health Affairs. 2016;35(1):28-35. doi:10.1377/hlthaff.2015.0253.

10. Kinosian B, Taler G, Boling P, Gilden D. Projected Savings and Workforce Transformation from Converting Independence at Home to a Medicare Benefit. Journal of the American Geriatrics Society. 2016;64(8):15311536. doi:10.1111/jgs.14176.

11. Ruiz S, Snyder LP, Rotondo C, Cross-Barnet C, Colligan EM, Giuriceo K. Innovative Home Visit Models Associated With Reductions In Costs, Hospitalizations, And Emergency Department Use. Health Affairs. 2017;36(3):425-432. doi:10.1377/hlthaff.2016.1305.

12. Stall N, Nowaczynski M, Sinha SK. Systematic Review of Outcomes from Home-Based Primary Care Programs for Homebound Older Adults. Journal of the American Geriatrics Society. 2014;62(12):2243-2251. doi:10.1111/jgs.13088.

13. Polat Ü, Kahraman BB, Kaynak I, Görgülü Ü. Relationship among health-related quality of life, depression and awareness of home care services in elderly patients. Geriatrics \& Gerontology International. 2016;16(11):1211-1219. doi:10.1111/ggi.12618.

14. Long-Term Care Providers and Services Users in the United States, 20152016. National Center for Health Statistics Vital and Health Statistics. https://www.cdc.gov/nchs/data/series/sr_03/sr03_43-508.pdf. Accessed March 27, 2019.

15. Medicare Claims Processing Manual. https://www.cms.gov/Regulationsand-Guidance/Guidance/Manuals/Downloads/clm104c12.pdf. Accessed December 29, 2018. 